\title{
Managing career moves
}

\author{
Chasing Stars: The Myth of Talent and the \\ Portability of Performance \\ by Boris Groysberg \\ Princeton University Press: 2010 \\ 464 pp. \$35, £24.95
}

Scientific excellence is widely believed to result from an individual's talents and creativity, rather than from their circumstances. In today's era of mobility, top talent in any discipline seems free to glide from institution to institution in search of the best rewards. Not so fast, says Boris Groysberg of Harvard Business School in Boston, Massachusetts. In Chasing Stars, he finds that talent is not always portable and can be surprisingly contextdependent.

Groysberg studies US stockmarket analysts, a population whose individual success is rated each year by industry publications and whose work is comparable across firms. Like science researchers, analysts' primary products are reports and they often switch employers during their careers. Groysberg tracked the movements of 799 analysts through interviews and by using ranking data from 1988-96. He found that top talent is not as transferable as either the employers or the stars themselves want to believe.

Compared with peers who stayed put, star analysts who switched firms experienced, on average, significant and lasting declines in performance. The declines were greatest for those who were recruited from top firms to companies of lower reputation, and for those who were recruited to beef up an area of subjectmatter weakness at the new firm. By contrast, analysts who moved from weaker to stronger firms, or who moved to exploit their own strengths or the strengths of the new company, suffered little. Interestingly, women analysts in Groysberg's study were less likely to experience declining performance after moving than their male counterparts.

In general, Groysberg suggests, professionals tend to overestimate their own contribution to their performance and underestimate the role of their employer's capabilities and resources in supporting it. Stars are particularly susceptible to thinking that their achievements are theirs alone. Failing to research a new firm adequately, choosing a firm for purely monetary reasons or failing to assess the long-term perspective can lead an otherwise brilliant individual to a disastrous career move. Groysberg speculates that the lesser impact for women analysts may be because they have developed stronger external relationships and scrutinize new positions more thoroughly in order to succeed in this male-dominated industry.

The study has implications for science careers. As a group that emphasizes exceptional individual talent, scientists may fail to recognize the contribution that setting can make to success. The quality of graduate students, postdocs and technicians may be more a function of the calibre of the institution than of any group leader. Similarly, research institutions seeking to move up in the rankings may be tempted to simply hire a handful of stars from elsewhere. However, if the stars are not well supported or do not fit, the result is likely to be disappointing on both sides. For graduate students and postdocs, managing talent portability is vital.

Chasing Stars highlights the key factors that improve the odds of successful job transitions. Build a network that extends beyond the confines of your research group and department. Evaluate the cultural and intellectual attributes and resources of a potential employer. Value those things above the monetary compensation in any offer package.

Peter S. Fiske is chief executive officer of PAX

Water Technologies, San Rafael, California 94901, USA, and author of Put Your Science to Work. e-mail: peterfiske@yahoo.com

\section{Medical treasures on show}

Läke Konst (Art of Medicine)

From 8 May until 29 August 2010

Waldemarsudde Museum, Stockholm

Marking the 200th anniversary this year of Stockholm's Karolinska Institute - Sweden's leading medical university - are more than 100 rare medical illustrations from its historic collection, on display at Stockholm's Waldemarsudde Museum.

From Andreas Vesalius's anatomical depictions to digitally enhanced visualizations of the human body by photographer Lennart Nilsson, the exhibition Läke Konst (Art of Medicine) highlights beautiful and unusual medical images dating from the fifteenth century to the present day. Drawn from the 35,000 rare books held by the institute's Hagströmer Library, many of the illustrations have not been exhibited before.

On show are hand-coloured woodcuts from sixteenth-century botanical books; copperplate engravings from seventeenth-century anatomical atlases; and eighteenth-century plates of microscope views, revealing objects that are invisible to the naked eye. Developments in obstetrics, surgery, pathology and ophthalmology are explored, as well as social issues such as the depiction of people with certain conditions as 'monsters'.

One woodcut is particularly striking: a sixteenthcentury child's eyes peer

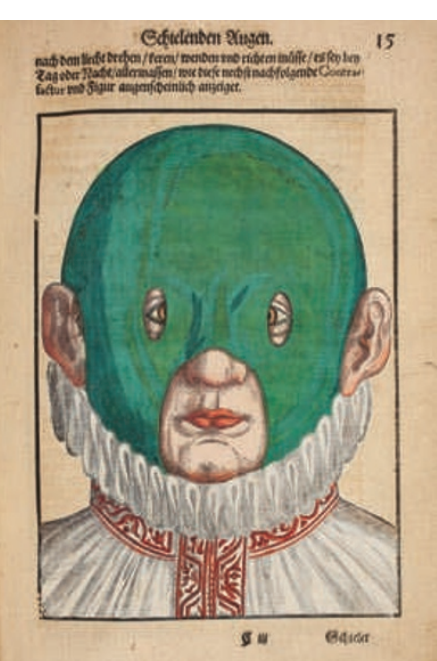

A sixteenth-century cure for a squint. and finely bound by Jakob Krause, a famous German bookbinder of the Renaissance, this special edition "is probably a presentation copy", explains curator Ove Hagelin, director of the Hagströmer Library. Once belonging to aristocrat and politician Peter Vok of Rosenberg in the Kingdom of Bohemia (now the Czech Republic), the book was brought to Sweden in the seventeenth century when his extensive library was claimed as booty following the Thirty Years' War.

"Like an archaeological out from behind a green mask (pictured), worn as a cure for squinting. The boy is depicted in Ophthalmodouleia, a text on eye surgery published in 1583 by George Bartisch, the founder of modern ophthalmology. With its pages delicately hand coloured object, each copy of an old book is unique and can tell the attentive researcher a lot more besides the author and his text," Hagelin concludes.

Marta Paterlini is a writer based in Stockholm. e-mail: martapaterlini@gmail.com 